\title{
HUBUNGAN KEPESERTAAN BPJS KESEHATAN DAN KUALITAS PELAYANAN BIDAN DENGAN CAKUPAN KUNJUNGAN PADA IBU HAMIL TRIMESTER III DI PUSKESMAS KECAMATAN CISOKA KABUPATEN TANGERANG TAHUN 2017
}

\author{
Eka Mardiana Afrilia ${ }^{1}$,Putri Aprilianty Solehah ${ }^{2}$ \\ Universitas Muhammadiyah Tangerang \\ Email : eka@fikes-umt.ac.id
}

\begin{abstract}
ABSTRAK
Badan Penyelenggara Jaminan Sosial (BPJS) bertujuan untuk memenuhi kebutuhan kesehatan masyarakat dan diberikan pada setiap orang yang telah membayar iuran maupun yang dibayarkan oleh pemerintah. Pelayanan kebidanan adalah pelayanan yang diberikan sesuai tugas dan tanggung jawab praktik profesi bidan dalam memberikan pelayanan secara komprehensif untuk meningkatkan kesehatan ibu dan anak masyarakat yang memberikan kepuasan pelanggan baik secara mandiri dan kolaborasi, oleh karena itu setiap wanita hamil perlu memerlukan sedikitnya empat kali kunjungan selama periode antenatal yaitu satu kali kunjungan selama trimester pertama (sebelum 14 minggu), satu kali kunjungan selama trimester kedua (antara minggu 14-28) dan dua kali kunjungan selama trimester ketiga (28-36). Desain penelitian yang digunakan adalah deskriptif analitik dengan pendekatan cross sectional. Populasi dalam penelitian adalah semua Ibu hamil yang ada di Puskesmas Kecamatan Cisoka pada bulan Mei Tahun 2017 berjumlah 102 orang, dan teknik sampel yang digunakan yaitu teknik accidental sampling sebanyak 51 responden. Data yang diperoleh dalam penelitian ini diolah dengan menggunakan uji chi-square dengan derajat kemaknaan $(\alpha=0,05)$. Hasil penelitian menunjukkan bahwa Kepesertaan BPJS Kesehatan dengan cakupan ibu hamil trimester III lengkap $(23,1 \%)$, kualitas pelayanan bidan dengan cakupan ibu hamil trimester III lengkap $(25,7 \%)$, dari analisa bivariat diperoleh hasil ada hubungan yang signifikan antara kepesertaan BPJS Kesehatan ( $p$ value $=0,045$ ) nilai OR 0,277, kualitas pelayanan bidan ( $p$ value $=0,027$ ) nilai OR 0,208 dengan cakupan ibu hamil trimester III. Simpulan yang didapat bahwa kepesertaan adalah faktor yang terbesar untuk meyebabkan cakupan kunjungan ibu hamil trimester III saran untuk dipuskesmas Kabupaten Tangerang untuk lebih sering memberikan penyuluhan kepada ibu hamil tentang pentingnya pemeriksaan kehamilan secara lengkap sehingga ibu hamil dapat memeriksakan kehamilanya difasilitas kesehatan.
\end{abstract}

Kata Kunci : Kepesertaan BPJS Kesehatan,Kualitas Pelayanan Bidan, Cakupan kunjungan ibu hamil trimester III

Daftar bacaan : 47 (2007-2016)

\begin{abstract}
The Social Security Administering Body (BPJS) aims to meet the public health needs and is provided to everyone who has paid contributions or paid by the government. Midwifery services are services provided in accordance with the duties and responsibilities of the midwife's professional practice in providing
\end{abstract}


comprehensive services to improve the health of mothers and children of the community that provide customer satisfaction both independently and collaboratively therefore every pregnant woman needs to require at least four visits during the antenatal period One visit during the first trimester (before 14 weeks), one visit during the second trimester (between weeks 14-28) and two visits during the third trimester (28-36). The research design used was analytical descriptive with cross sectional approach. The population in the study were all pregnant women in Cisoka District Health Center in May of 2017 amounted to 102 people and the sample technique used was accidental sampling technique of 51 respondents. Data obtained in this study were processed by using chi-square test with degree of significance $(\alpha=0,05)$. The results showed that the participation of BPJS Health with coverage of complete third trimester pregnant woman $(23,1 \%)$, midwife service quality with complete trimester pregnant mother coverage $(25,7 \%)$, from bivariate analysis obtained result there is significant relationship between BPJS membership Health ( $p$ value $=0,045$ ) OR value 0,277, service quality of midwife ( $p$ value $=0,027$ ) OR 0,208 with coverage of pregnant mother of trimester III. The conclusion is that participation is the biggest factor to make coverage of visit of third trimester pregnant woman suggestion for puskesmas of tangerang regency to more often give counseling to pregnant mother about the importance of complete pregnancy examination so that pregnant woman can check their pregnancy in health facility.

\section{Keywords : BPJS Health Participation, Midwife Service Quality, Coverage of third trimester pregnant women visit}

Reading List : 47 (2007-2016)

\section{PENDAHULUAN}

Angka Kematian Ibu bersama dengan Angka Kematian Bayi senantiasa menjadi indikator keberhasilan pembangunan pada sektor kesehatan. Target AKI di Indonesia pada tahun 2015 adalah 102 kematian per 100.000 kelahiran hidup. Sementara itu berdasarkan Survei Demografi dan Kesehatan Indonesia (SDKI) tahun 2012, Angka Kematian Ibu (AKI) (yang berkaitan dengan kehamilan, persalinan, dan nifas) sebesar 359 per 100.000 kelahiran hidup. World Health Organization (WHO), mendorong seluruh negara mengembangkan Jaminan Kesehatan untuk semua penduduknya (Universal Health Coverage). Dengan jaminan kesehatan tersebut semua penduduk di negara yang mengembangkan jaminan kesehatan ini termasuk peserta Jaminan Kesehatan.
Jaminan Kesehatan Nasional adalah hak yang harus diperoleh seluruh Warga Negara Indonesia, sebagaimana diamanatkan dalam undang-undang Dasar 1945 pasal 28 dan undang-undang nomor 36 tahun 2009 tentang kesehatan bahwa setiap individu, keluarga dan masyarakat berhak memperoleh perlindungan terhadap kesehatannya, dan negara bertanggung jawab mengatur agar terpenuhi hak hidup sehat bagi penduduknya termasuk bagi masyarakat miskin dan tidak mampu. Upaya mewujudkan hak tersebut pemerintah harus menyelenggarakan pelayanan kesehatan yang merata, adil dan terjangkau bagi seluruh lapisan masyarakat. Jaminan Kesehatan Nasional adalah program pemerintah yang bertujuan memberikan kepastian jaminan kesehatan 
yang menyeluruh bagi seluruh rakyat Indonesia untuk dapat hidup sehat produktif dan sejahtera (BPJS Kesehatan, 2014).

Berdasarkan penelitian bahwa terdapat hubungan antara mutu pelayanan kesehatan BPJS dengan kepuasan pasien, hal tersebut di dukung dari hasil penelitiannya yaitu dari total 64 responden yang di teliti, terdapat 44 responden $(68,8 \%)$ mengatakan pelayanan kesehatan BPJS kurang baik, dan pada kepuasan

\section{METODE}

Metode yang digunakan dalam penelitian ini menggunakan pendekatan kuantitatif dengan jenis rancangan penelitian Cross Sectional, yaitu jenis penelitian yang menekankan pada waktu pengukuran atau observasi data variabel independen dan variabel dependen hanya satu kali pada satu saat (Nursalam, 2003).

\section{HASIL}

Dalam penelitian ini tehnik sampel yang di gunakan yaitu Accidental sampling yaitu tehnik penentuan sampel berdasarkan menggunakan uji chi-square dengan derajat kemaknaan $(\alpha=0,05)$. pasien sebanyak 36 responden $(56,2 \%)$ mengatakan kurang puas dengan pelayanan kesehatan BPJS ( Ningrum, 2014).

Berdasarkan hal tersebut di atas maka penulis tertarik untuk melakukan penelitian dengan judul "Hubungan Kepesertaan BPJS Kesehatan dan Kualitas Pelayanan Bidan dengan Cakupan Kunjungan Pada Ibu Hamil Trimester III Dipuskesmas Kecamatan Cisoka Tahun 2017”.

kebetulan, yaitu siapa saja secara kebetulan bertemu dengan peneliti dapat digunakan sebagai sampel.

\section{Analisis Data Univariat}

Pada bab ini akan diuraikan hasil data penelitian tentang Hubungan kepesertaan BPJS Kesehatan dengan kualitas pelayanan bidan di Puskesmas Kecamatan Cisoka Kabupaten Tangerang Provinsi Banten Tahun 2017. Berdasarkan data yang diperoleh pada Bulan Mei 2017. diperoleh data dari 51 responden. Pengambilan data menggunakan angket/ kuesioner.

Tabel 1

Distribusi Frekuensi Kepesertaan BPJS Kesehatan

Puskesmas Kecamatan Cisoka Tahun 2017

\begin{tabular}{lcc}
\hline Kepesertaan BPJS Kesehatan & Frekuensi f & Presentasi $\%$ \\
\hline Ya & 26 & $51 \%$ \\
Tidak & 25 & $49 \%$ \\
Total & 51 & $100 \%$ \\
\hline \multicolumn{2}{c}{ Sumber data: Hasil Pengambilan Data pada bulan Agustus Tahun 2017 }
\end{tabular}

Berdasarkan Tabel 1 diatas diketahui bahwa dari 51 responden ibu hamil trimester III yang menjadi peserta BPJS
Kesehatan sebesar jumlah $51 \%$ sedangkan yang tidak menjadi peserta BPJS Kesehatan sebesar jumlah $49 \%$. 
Tabel 2

Distribusi Frekuensi Kualitas Pelayanan Bidan di Puskesmas Cisoka Kabupaten Tangerang Tahun 2017

\begin{tabular}{lcc}
\hline \multicolumn{1}{c}{ Kualitas Pelayanan } & Frekuensi f & Presentasi $\%$ \\
\hline Tinggi & 35 & $68,6 \%$ \\
Rendah & 16 & $31,4 \%$ \\
Total & 51 & $100 \%$ \\
\hline
\end{tabular}

Sumber data : HasilPengambilan data pada bulan Agustus Tahun 2017

Berdasarkan Tabel 2 diatas diketahui bahwa dari 51 responden di Puskesmas Kecamatan Cisoka, kualitas pelayanan bidan yang tinggi sebesar 68,6\%, sedangkan kualitas pelayanan bidan yang rendah sebesar $31,4 \%$.

Tabel 3

Distribusi Frekuensi Cakupan Kunjungan Pada Ibu Hamil Trimester III di Puskesmas Cisoka Kabupaten Tangerang Tahun 2017

\begin{tabular}{lcc}
\hline $\begin{array}{c}\text { Kunjungan ibu hamil } \\
\text { Trimester III }\end{array}$ & Frekuensi (f) & Persentase \\
& & $(\%)$ \\
\hline Lengkap & 19 & 37,3 \\
Tidak Lengkap & 32 & 62,7 \\
Jumlah & 51 & 100 \\
\hline
\end{tabular}

Berdasarkan tabel 5.3 diatas diketahui bahwa dari 51 responden di Puskesmas Kecamatan Cisoka, cakupan kunjungan ibu hamil trimester III yang lengkap sebesar $37,3 \%$, sedangkan yang tidak lengkap sebesar $62,7 \%$

Tabel 4

Hubungan Antara Kepesertaan BPJS Kesehatan Terhadap Cakupan

Kunjungan Ibu Hamil Trimester III di Puskesmas Kecamatan Cisoka Tahun 2017

\begin{tabular}{|c|c|c|c|c|c|c|c|c|}
\hline \multirow{3}{*}{$\begin{array}{c}\text { Kepesertaan } \\
\text { BPJS Kesehatan }\end{array}$} & \multicolumn{4}{|c|}{$\begin{array}{c}\text { Cakupan Kunjungan Ibu Hamil } \\
\text { Trimester III }\end{array}$} & \multicolumn{2}{|c|}{ Jumlah } & \multirow[t]{2}{*}{$\begin{array}{c}\mathrm{P} \\
\text { Value }\end{array}$} & \multirow[t]{2}{*}{$\begin{array}{c}\text { OR } \\
(\mathrm{CI} 95 \%)\end{array}$} \\
\hline & \multicolumn{2}{|c|}{ Lengkap } & \multicolumn{2}{|c|}{ Tidak Lengkap } & \multirow[b]{2}{*}{$\mathrm{f}$} & \multirow[b]{2}{*}{$\%$} & & \\
\hline & $\mathrm{F}$ & $\%$ & $\mathrm{~F}$ & $\%$ & & & \multirow[t]{2}{*}{0,045} & 0,277 \\
\hline $\mathrm{Ya}$ & 6 & 23,1 & 20 & 76,9 & 26 & 100 & & $(0,083$ \\
\hline Tidak & 13 & 52,0 & 12 & 48,0 & 25 & 100 & & $-0,922)$ \\
\hline Jumlah & 19 & 37,2 & 32 & 62,7 & 51 & 100 & & \\
\hline
\end{tabular}


Hubungan kepersetaan BPJS Kesehatan dengan Cakupan Kunjungan pada ibu hamil trimester III dikategorikan lengkap dengan kepersetaan BPJS sebanyak $6(23,1 \%)$ dan tidak memiliki kepersetaan BPJS Kesehatan sebanyak 13 $(52,0 \%)$ sedangkan cakupan kunjungan pada ibu hamil trimester III dikategorikan tidak lengkap dengan Kepersetaan BPJS sebanyak $20(76,9 \%)$ dan tidaak memiliki kepersetaan BPJS kesehatan 12 (48,0\%).

Dari hasil analisis bivariat dengan menggunakan uji chi-square di peroleh nilai $p$ value $=0,045$ dimana nilai $p$ value lebih kecil dari pada $\propto(0,05)$ maka ada hubungan antara kepesertaan BPJS kesehatan dengan cakupan kunjungan ibu hamil trimester III di Puskesmas Kecamatan Cisoka Kabupaten Tangerang tahun 2017.

Hasil analisis data di dapatkan OR = $0,277(0,083-0,922)$, Hal ini berarti ibu hamil trimester III yang tidak menjadi peserta BPJS Kesehatan memiliki kecenderungan lebih besar untuk melakukan kunjungan ibu hamil trimester III sebesar 0,277 kali di bandingkan dengan ibu hamil yang menjadi peserta BPJS kesehatan.

Tabel 5

Hubungan Antara Kualitas Pelayanan Bidan Terhadap Cakupan Kunjungan Ibu Hamil Trimester III Di Puskesmas Kecamatan Cisoka Tahun 2017

\begin{tabular}{|c|c|c|c|c|c|c|c|c|}
\hline \multirow{3}{*}{$\begin{array}{c}\text { Kualitas } \\
\text { Pelayanan } \\
\text { Bidan }\end{array}$} & \multicolumn{4}{|c|}{$\begin{array}{c}\text { Cakupan Kunjungan Ibu Hamil } \\
\text { Trimester III }\end{array}$} & \multicolumn{2}{|c|}{ Jumlah } & \multirow[t]{3}{*}{$\begin{array}{c}\mathrm{P} \\
\text { Value }\end{array}$} & \multirow[t]{3}{*}{$\begin{array}{c}\text { OR } \\
\text { CI } 95 \%\end{array}$} \\
\hline & \multicolumn{2}{|c|}{ Lengkap } & \multicolumn{2}{|c|}{ Tidak Lengkap } & \multirow[b]{2}{*}{$\mathrm{F}$} & \multirow[b]{2}{*}{$\%$} & & \\
\hline & $\mathrm{f}$ & $\%$ & $\mathrm{~F}$ & $\%$ & & & & \\
\hline Tinggi & 9 & 25,7 & 26 & 74,3 & 35 & 100 & \multirow{3}{*}{0.027} & \multirow{3}{*}{$\begin{array}{c}0,208 \\
(0,059- \\
0,736)\end{array}$} \\
\hline Rendah & 10 & 62,5 & 6 & 37,5 & 16 & 100 & & \\
\hline Jumlah & 19 & 37,3 & 32 & 62,7 & 51 & 100 & & \\
\hline
\end{tabular}

Hubungan kualitas pelayanan bidan dengan cakupan kunjungan pada ibu hamil trimester III dikategorikan lengkap dengan tinggi dalam kualitas pelayanan bidan sebanyak $9(25,7 \%)$ dan rendah dalam kualitas pelayanan bidan sebanyak 10 $(62,5 \%)$ sedangkan cakupan kunjungan pada ibu hamil trimester III yang tidak lengkap dengan tinggi dalam kualitas pelayanan bidan sebanyak $26(74,3 \%)$ dan rendah dalam kualitas pelayanan bidan sebanyak $6(37,5 \%)$.

Dari hasil analisis bivariat dengan menggunakan uji chi- square di peroleh nilai $p$ value $=0,027 \mathrm{di}$ mana nilai $\mathrm{p}$ value lebih kecil dari pada $\propto(0,05)$ maka Ha diterima ada hubungan antara kualitas pelayanana bidan dengan cakupan kunjungan ibu hamil trimester III di puskesmas kecamatan cisoka Tahun 2017.

Hasil analisis data di dapatkan OR = $0,208(0,059-0,736)$, Hal ini berarti ibu hamil trimester III dengankualitas pelayanan bidan yang tinggi memiliki kecenderungan lebih kecil 0,208 kali untuk tidak melakukan kunjungan ibu hamil trimester III dengan kualitas pelayanan bidan yang rendah. 


\section{PEMBAHASAN}

\section{Kepesertaan BPJS Kesehatan}

Dari Hubungan kepersetaan BPJS Kesehatan dengan Cakupan Kunjungan pada ibu hamil trimester III dikategorikan lengkap dengan kepersetaan BPJS sebanyak $6(23,1 \%)$ dan tidak memiliki kepersetaan BPJS Kesehatan sebanyak 13 $(52,0 \%)$ sedangkan cakupan kunjungan pada ibu hamil trimester III dikategorikan tidak lengkap dengan Kepersetaan BPJS sebanyak $20(76,9 \%)$ dan tidaak memiliki kepersetaan BPJS kesehatan 12 (48,0\%).

Menurut Undang-Undang Nomor 40 tahun 2004 tentang sistem jaminanan sosial nasional (SJSN) di amanatkan bahwa seluruh penduduk wajib menjadi peserta jaminan kesehatan termasuk warga negara asing yang tinggal di Indonesia lebih dari enam bulan. Pengaruh kepesertaan BPJS Kesehatan terhadap ibu hamil yang di bantu oleh tenaga kesehatan. Menurut kementrian kesehatan republik indonesia (2011), menyatakan bahwa jaminan kesehatan dalam BPJS adalah pelayanan ibu hamil yang diberikan oleh pemerintah.

Berdasarkan hasil penelitian " Annisa Sri Wahyu Melina " dengan judul “ Hubungan penggunaan Jaminan Kesehatan Nasional dengan capaian target cakupan layanan ibu hamil di puskesmas bangun tapan Kab. Bantul 2016, dengan nilai $p$ value $0,000<0,05$ sehingga disimpulkan adanya hubungan penggunaan Jaminan Kesehatan Nasional dengan capaian target kunjungan ibu hamil di puskesmas bangun tapal Kab. Bantul 2016.

Dari hasil analisis bivariat dengan menggunakan uji chi-square di peroleh nilai $p$ value $=0,045$ dimana nilai $p$ value lebih kecil dari pada $\propto(0,05)$ maka ada hubungan antara kepesertaan BPJS kesehatan dengan cakupan kunjungan ibu hamil trimester III di Puskesmas Kecamatan Cisoka Kabupaten Tangerang tahun 2017.

\section{Kualitas Pelayanan Bidan}

Hubungan kualitas pelayanan bidan dengan cakupan kunjungan pada ibu hamil trimester III dikategorikan lengkap dengan tinggi dalam kualitas pelayanan bidan sebanyak $9(25,7 \%)$ dan rendah dalam kualitas pelayanan bidan sebanyak 10 $(62,5 \%)$ sedangkan cakupan kunjungan pada ibu hamil trimester III yang tidak lengkap dengan tinggi dalam kualitas pelayanan bidan sebanyak $26(74,3 \%)$ dan rendah dalam kualitas pelayanan bidan sebanyak $6(37,5 \%)$.

Kualitas pelayanan merupakan upaya pemenuhan kebutuhan dan keinginan konsumen serta ketepatan penyampaiannya dalam mengimbangi harapan konsumen (Tjiptono, 2007).

Hal ini sejalan dengan Kotler (2002), Kualitas pelayanan adalah segala bentuk aktifitas yang dilakukan oleh perusahaan guna memenuhi harapan konsumen. Pelayanan dalam hal ini dapat diartikan sebagai jasa atau survice yang di sampaikan oleh pemilik jasa yang berupa kemudahan, kecepatan, hubungan, kemampuan dan keramah tamahan yang ditujukan melalui sikap dan sifat dalam memberikan pelayanan untuk kepuasan konsumen.

Menurut Sarwono (2015), memberikan kesempatan kepada bidan dan petugas kesehatan lainnya untuk pelatihan dan pengembangan sebagai upaya meningkatkan kompetensinya.pelatihan tersebut termasuk pelatihan tentang tehnik komunikasi yang efektif dan pengelolaan program KIA, agar mampu menyampaikan berbagi informasi yang dibutuhkan oleh ibu hamil untuk memelihara kehamilan yang sehat dan pelatihan pelayanan Antenatal comprehensif dan pelayanan prima untuk meningkatkan kemampuan bidan dalam memberikan pelayanan Antenatal yang lebih berkualitas dengan kualitas pelayanan bidan pada ibu hamil yang tinggi diharapkan dapat terus meningkat. 
Berdasarkan hasil penelitian " Aliah Dwi Kurnia Abu, Yuli kusumaati, Kusuma estu werdani " yang berjudul " Hubungan Karateristik bidan dengan mutu pelayanan Antenatal Care 2015 " berdasarkan standar opresional, dengan nilai $p$ value $0,04<0,05$ sehingga disimpulkan adanya hubungan yang signifikan antara hubungan karateristik bidan dengan mutu pelayanan Antenatal Care 2015.

Dari hasil analisis bivariat dengan menggunakan uji chi- square di peroleh nilai $p$ value $=0,027 \mathrm{di}$ mana nilai $\mathrm{p}$ value lebih kecil dari pada $\propto(0,05)$ maka $\mathrm{Ha}$ diterima ada hubungan antara kualitas pelayanana bidan dengan cakupan kunjungan ibu hamil trimester III di puskesmas kecamatan cisoka Tahun 2017.

\section{KESIMPULAN}

Berdasarkan hasil penelitian yang dilakukan di Puskesmas Kecamatan Cisoka Tahun 2017, diperoleh hasil :

Ibu hamil yang tidak menjadi peserta BPJS Kesehatan terhadap cakupan kunjungan ibu hamil trimester III di Puskesmas Kecamatan Cisoka Tahun 2017 sebesar $48,0 \%$ atau sebanyak 25 orang.

Ibu hamil yang menjadi peserta BPJS Kesehatan terhadap cakupan kunjungan ibu hamil trimester III sebesar $51 \%$, kualitas pelayanan bidan terhadap cakupan ibu hamil trimester III yang tinggi sebesar $68,6 \%$ dan cakupan kunjungan ibu hamil trimester III yang lengkap sebesar 37,3\%.

Berdasarkan hasil uji statistik terhadap 2 variabel yang sudah diteliti, didapatkan hasil bahwa terdapat hubungan yang bermakna antara Kepesertaan BPJS Kesehatan $(\mathrm{p}$-value $=0,045)$, kualitas pelayanan bidan ( $\mathrm{p}$-value $=0,027$ ) dengan cakupan kunjungan ibu hamil trimester III di Puskesmas Kecamatan Cisoka tahun 2017.

\section{SARAN}

\section{Bagi Puskesmas}

Dapat memberikan solusi BPJS kesehatan karena merupakan salah satu bentuk kegiatan pemberdayaan masyarakat, pemberdayaan adalah strategi promosi kesehatan yang ditunjukan langsung kepada masyarakat. Penyuluhan merupakan upaya agar masyarakat berperilaku atau mengdopsi perilaku kesehatan dengan cara memberikan bujukan, himbauan, ajakan, memberi informasi yang akan memberikan kesadaran pada ibu hamil.

Dapat memberikan masukan kepada tenaga kesehatan untuk lebih memotivasi ibu hamil dalam meningkatkan kunjungan antenatal care, selain itu dukungan keluarga (suami, orang tua, dan orang terdekat) ibu hamil perlu ditingkatkan guna memberikan dukungan kepada ibu hamil. Akses pelayanan kesehatan khususnya ibu hamil perlu ditingkatkan dan meningkatkan pengetahuan kepada masyarakat khususnya ibu hamil tentang pentingnya pemeriksaan selama kehamilan. Hasil penelitian ini pula dapat dijadikan rekomendasi untuk melakukan penelitian tentang persepsi ibu hamil tentang kehamilan dan mengetahui respon ibu hamil dan suami dengan adanya tindakan antenatal care.

\section{Bagi Tenaga Kesehatan}

Diharapkan tenaga kesehatan memberikan pelayanan yang lebih baik lagi terhadap pasien, dapat mendorong atau memberikan pengetahuan kepada pasien ibu hamil tentang antenatal care yang lengkap.

\section{Bagi Institusi Pendidikan}

Menambah bahan informasi yang dapat dijadikan referensi bagi pengembangan ilmu atau penulisan lebih lanjut bagi yang membutuhkannya khususnya tentang kejadian penyakit menular seksual pada wanita. 


\section{Bagi Penulis}

Untuk menambah wawasan dalam penambahan ilmu pengetahuan dan pengalaman penulis dalam penerapan ilmu yang diperoleh Dapat meningkatkan pengetahuan dan keterampilan secara terusmenerus supaya dapat meningkatkan mutu

\section{DAFTAR PUSTAKA}

Andrijono, 2009. Pelayanan kebidanan Edisi Ketiga. Divisi Onkologi Departemen Obstetri-Ginekologi FKUI : Jakarta.

Arikunto,S. 2010. Prosedur penelitian. Rineka Cipta: Jakarta.

Ayu, M. 2016. Hubungan kepesertaan bpjs kesehatan dan cakupan ibu hamil pdi Kelurahan Kotabaru Wilayah Kerja Puskesmas gonosari II Yogyakarta..Fakultas Ilmu Kesehatan di Universitas Aisyiyah Yogyakarta. Skripsi

BPJS. 2015. Peningkatan partisipasi BPJS Kesehatan . Jakarta

Chaplin, J.P. 2006. Kamus Lengkap Psikologi. PT. Raja Grafindo : Jakarta.

Depkes RI 2012. Profil KesehatanIndonesia. Di akses http://www.Depkes.go.idTanggal 16 Juli 2017.

Emilia.,O. 2010. Kualitas pelayanan. Media Pressindo : Yogyakarta.

Gale, D \& Charette, J. 2000. Rencana asuhan kebidanan onkologi, Alihbahasa I Made Kasiasa. EGC : Jakarta.

Hidayat, A.A. 2008. Metode Penelitian Keperawatan dan Teknik Analisa Data. Salemba Medika : Jakarta.

Kementerian Kesehatan RI. 2013. Riset Kesehatan Dasar (RISKESDAS). Badan Litbang Kemenkes RI : Jakarta. Komalasari, K. W. 2012. Hubungan Tingkat pengetahuan mahasiswa fakultas kedokteran Universitas penelitian dimasa yang akan datang. memperoleh manfaat pemeliharaan kesehatan dan perlindungan dalam memenuhi kebutuhan dasar kesehatannya yang diselenggarakan oleh BPJS Kesehatan yang handal, unggul dan terpercaya.

Diponegoro angkatan 2011 terhadap kepesertaan bpjs kesehatan.Jurnal

Maharani, S. 2012. Mengenal 13 kualitas pelayanan kebidanan.

Katahati : Jakarta.

Nasir, A, dkk. 2011.Metodologi Penelitian Kesehatan.Nuha Medika : Jakarta.

Notoatmodjo, S.2010. Promosi Kesehatan dan Ilmu Perilaku. Rineka Cipta: Jakarta.

Notoatmodjo, S. 2010. Metodologi Penelitian Kesehatan. Rineka Cipta : Jakarta.

Notoatmodjo, S. 2013. Metode Penelitian Pendidikan (pendekatan kuantitatif, kualitatif.Rineka Cipta : Jakarta.

Notoatmodjo, S. 2005. Ilmu kesehatan masyarakat. Rineka Cipta : Jakarta.

Nursalam. 2008.Metodologi Penelitian Ilmu Keperawatan: Pedoman Skripsi \& Tesis dan Instrumen Penelitian Keperawatan. Salemba Raya Medika : Jakarta.

Prawirohardjo, S. 2010. Ilmu Kebidanan. Bina Pustaka Sarwono Prawirohardjo : Jakarta.

Robbins, S dan Coulter, M. 2007. Manajemen, Edisi Kedelapan: Penerbit PT. Indeks : Jakarta.

Suarli, S \& Bachtiar. 2009. Manajemen Keperawatan dengan Pendekatan

Praktik. Erlanggga : Jakarta.

Sugiyono. 2010. Statistika Untuk Penelitian. Alfabeta : Bandung.

Sugiyono. 2013. Metode Penelitian Pendidikan (pendekatan kuantitatif, kualitatif

dan $R \& D)$. Alfabeta : Bandung.

Indonesia RS Dr. Cipto Mangunkusumo, Jakarta. 
Modifikasi Lawrence Green dalam Notoatmodjo, 2010.

Mubarak, Wahit Iqbal dan Nurul Chayatin (2012). Buku ajar kebutuhan dasar manusia: teori dan aplikasi dalam praktik. Jakarta: EGC.

Notoatmodjo S, 2010, Perilaku Kesehatan Dalam Ilmu Kesehatan Masyarakat Prinsip-Prinsip Dasar, Cetakan ke 2, Penerbit Rineka Cipta. Jakarta.

Proverawati,Atikah.2010. Imunisasi dan Vaksinasi.Jakarta: Nuha Offset

Ranuh dkk. Buku Imunisasi di Indonesia. Jakarta : Satgas Imunisasi IDAI, 2011.

Riset Kesehatan Dasar (Riskesdas). (2013). Badan Penelitian dan Pengembangan Kesehatan Kementerian RI tahun 2013.Diakses: 19 Januari 2017.

Sugiarto. 2007. Peran KMS Dalam Menentukan Kesehatan Gizi Anak di Kecamatan Ciputat Tangerang. 20 Januari 2007.
Sugiyono. 2012. Metode Penelitian Pendidikan Pendekatan Kuantitatif, Kualitatif. Bandung. Alfabeta.

TM Thaib, Dora Darussalam, Sulaiman Yusuf, Rusdi Andid, 2013. Dalam Jurnal "Cakupan Imunisasi Dasar Anak Usia 1-5 tahun dan Beberapa Faktor yang berhubungan di Poliklinik Anak Rumah Sakit Ibu dan Anak (RSIA) Banda Aceh".

Vidia As Nurani, 2013. Dalam Jurnal "Faktor-faktor yang berhubungan dengan kelengkapan imunisasi dasar pada bayi di desa truko kecamatan kangkung kabupaten kendal tahun 2013".

Yuliana Makamban, 2014. Dalam Jurnal "Faktor yang mempengaruhi kelengkapan imunisasi dasar lengkap pada bayi di wilayah kerja puskesmas antara kota makassar, 2014". 